\title{
An efficient methodology to estimate probabilistic seismic damage curves
}

Yeudy F. Vargas ${ }^{1}$, Luis G. Pujades², Alex H. Barbat ${ }^{3}$ and Jorge E. Hurtado ${ }^{4}$

${ }^{1}$ Universidad Politécnica de Cataluña, Department of Civil and Environmental Engineering, Jordi Girona 1-3, Barcelona, Spain. Researcher.

${ }^{1}$ Universidad Politécnica de Cataluña, Department of Civil and Environmental Engineering, Jordi Girona 1-3, Barcelona, Spain. Full profesor.

${ }^{2}$ Universidad Politécnica de Cataluña, Department of Civil and Environmental Engineering, Jordi Girona 1-3, Barcelona, Spain. Full profesor.

${ }^{3}$ Universidad Nacional de Colombia, Department of Civil Engineering, Manizales, Colombia. Full profesor

\section{Abstract}

The incremental dynamic analysis is a powerful methodology which can be easily extended for calculating probabilistic seismic damage curves. These curves are metadata to assess the seismic risk of structures. Although this methodology requires a relevant computational effort, it should be the reference to correctly estimate the seismic risk of structures. Nevertheless, it would be of high practical interest to have a simpler methodology, based for instance on the pushover analysis, to obtain similar results to those based on the incremental dynamic analysis. In this article, the pushover analysis is used to obtain probabilistic seismic damage curves from the stiffness degradation and the energy of the nonlinear part of the capacity curve. A fully probabilistic methodology is tackled by means of Monte Carlo simulations, with the purpose of establishing that the results based on the simplified proposed approach are compatible with those obtained with the incremental dynamic analysis. Comparisons between the results of both approaches are included for a low-to-mid-rise reinforced concrete building. The proposed methodology significantly reduces the computational effort when calculating probabilistic seismic damage curves.

\section{Introduction}

In the last decades, several approaches have been developed for estimating the seismic risk of structures. One of these is based on the Vulnerability Index Method. In this method, the seismic hazard is considered 
by means of macroseismic intensities, Egozcue et al. 1991, and the structural behavior by means of vulnerability indices, Lantada et al. 2010, Barbat et al. 2011, Lagomarsino et al. 2006. Another widely invoked method is based on the capacity spectrum method, CSM, developed by Freeman et al. 1975, Freeman 1998, and further developed by Fajfar and Gaspersic 1996, Chopra and Goel 1999, and Fajfar 1999, among others. In this method, the seismic action is considered by means of the elastic response spectrum, while the building capacity is represented by means of a capacity curve or a capacity spectrum. The capacity curve is calculated with an incremental nonlinear static analysis, commonly known as Pushover Analysis (PA in the sequel); it is also assumed that the structural response is dominated by the first mode of vibration. However, it is important to note that the capacity spectrum method has been further modified in order to include the effects of higher modes of vibration, Chopra and Goel 2002, Chopra et al 2004, Kreslin and Fajfar 2012.. More recently, the Incremental Dynamic Analysis method, IDA, is becoming a powerful tool for assessing the seismic behavior of buildings which allow to take into consideration the following aspects: 1) the nonlinear dynamic response of the structure; 2) the increments of the seismic intensity; and 3) the uncertainties related to the structural properties and to the seismic hazard. These aspects allow obtaining probabilistic damage curves, PDC, which are metadata for estimating seismic risk scenarios at urban level. Notice that to correctly estimate seismic risk scenarios, the uncertainties involved in the seismic hazard action and in the mechanical and geometrical properties of the structures should be considered. Nonetheless, the computational effort involved to carry out IDA can be very large, and the use of simplified methods is an urgent need of practical interest.

In this article a simplified method for calculating PDC, with an efficient approach based on the stiffness degradation and on the energy of the nonlinear part of the capacity curve, is proposed. The PDC obtained with this simplified approach fit with sufficient accuracy the PDC calculated via IDA method. The effectiveness of the simplified presented approach is tested for a low-to-mid-rise reinforced concrete framed building. The Monte Carlo method is used to perform the probabilistic calculations presented herein. 


\section{Incremental dynamic analysis}

A nonlinear dynamic analysis, NLDA, allows to simulate the time history response of a structure subjected to an earthquake. This analysis also allows to calculate the maxima of structural response variables like the displacement at the roof, the global damage index, among others. A method which uses NLDA as structural solver is the Incremental Dynamic Analysis, IDA, Vamvatsikos and Cornell 2002. IDA is generally performed with several earthquakes records increasingly scaled. The IDA method may be extended to include uncertainties in the structural properties, Vamvatsikos and Fragiadakis 2010, Vargas et al 2012, ensuing a very good approach to adequately estimate PDC. Groups of PDC are generally used to simulate seismic risk scenarios at urban areas. However, if uncertainties are included when employing IDA, it generally turns into a computationally costly method, Vargas et al. 2015. In spite of this, this section is devoted to explaining how IDA can be applied for obtaining PDC. A low-to-mid-rise reinforced building is considered as a testbed.

\subsection{Description of the studied building}

A reinforced concrete framed building has been designed and used as a testbed in order to perform the structural calculations proposed in this article. A sketch of this building is shown in Figure 1a. This figure also displays the geometrical dimensions of the building. Notice that, due to its symmetry, the building can be modeled as a two-dimensional structure by using a single frame (Figure 1b).
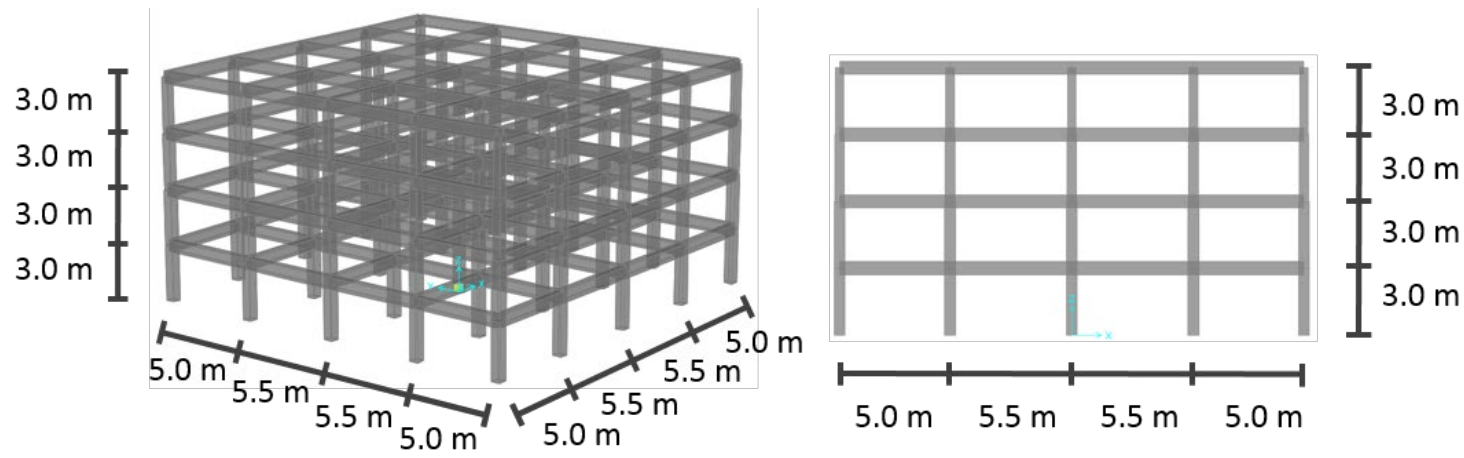
Figure 1 a) Building studied in this article and b) 2D model

The main characteristics of the beams and columns of the framed structure are given in Table 1 . The inelastic behavior of beams and columns elements follow the concept of the Gilberson one-component model, which allows hinges at one or both ends of the elastic central length of the member. In this model, the length of plastic hinges was assumed $5 \%$ of the length, $\mathrm{L}$, of the element; that is $0.05 \mathrm{~L}$. To consider the hysteretic cycle for flexure-failing mechanism in beams and columns, the modified Takeda hysteresis law, Otani 1974, has been considered. Yielding surfaces are defined by the bending moment-axial load interaction diagram for columns and bending moment-curvature for beams. The applied loads follow the recommendations given by the Eurocode 2, CEN 2004, for reinforced concrete structures. Notice that nonlinearities due to shear forces are not allowed because it has been assumed that the structural elements are well confined.

\begin{tabular}{|c|c|c|c|c|c|c|}
\hline & \multicolumn{3}{|c|}{ Columns } & \multicolumn{3}{c|}{ Beams } \\
\hline Story & $b(\mathrm{~m})$ & $h(\mathrm{~m})$ & $\rho$ & $b(\mathrm{~m})$ & $h(\mathrm{~m})$ & $\rho$ \\
\hline 1 & 0.5 & 0.5 & 0.03 & 0.45 & 0.6 & 0.0066 \\
\hline 2 & 0.5 & 0.5 & 0.02 & 0.45 & 0.6 & 0.0066 \\
\hline 3 & 0.45 & 0.45 & 0.015 & 0.45 & 0.6 & 0.0066 \\
\hline 4 & 0.4 & 0.4 & 0.015 & 0.45 & 0.6 & 0.0066 \\
\hline
\end{tabular}

Table 1 Characteristics of the elements of the studied building (Figure 1). $b, h$ and $\rho$ denote base, height and steel percentage of the cross sections of the structural elements, respectively.

\subsection{Mechanical properties of the materials as random variables}

Generally, the characteristic mechanical properties of concrete and steel are the values used in the design of reinforced concrete buildings. Design standards require characteristic strength values for the materials 
obtained during the quality control process, from compression and tension tests in concrete and steel samples, respectively. In order to meet the probabilistic approach of this article, the concrete compressive strength, $f c$, and the steel elastic modulus, $E s$, will be modeled as random variables. Table 2 presents the assumed mean, $\mu$, standard deviation, $\sigma$ and coefficient of variation (cov) of these random variables. Truncated normal distributions are considered, being the limits the mean value minus and plus 2.5 standard deviations. Thus, negative samples are not allowed for variables in Table 2. The coefficient of variation of the concrete compressive strength, fc, may vary from building to building, in the range $0.07-0.2$; the average value of this cov is about 0.15 , Melchers 1999 . However, this value depends on the quality control carried out during construction. For instance, a highly controlled concrete tends to exhibit a cov value close to 0.1 , Melchers 1999. For a mid-controlled concrete, the expected cov is about 0.15 . In this research, the cov for the concrete compressive strength has been assumed 0.15 . The coefficient of variation of the elastic modulus of the steel, Es, has been set to 0.1, Melchers 1999.

\begin{tabular}{|c|c|c|c|}
\hline Variable & $\boldsymbol{\mu}$ & $\sigma$ & cov \\
\hline$f_{\mathcal{C}}(\mathrm{kPa})$ & $2.1 \mathrm{E} 04$ & $3.15 \mathrm{E} 03$ & 0.15 \\
\hline$E S(\mathrm{kPa})$ & $2 \mathrm{E} 08$ & $2 \mathrm{E} 07$ & 0.1 \\
\hline
\end{tabular}

Table 2 Characteristics of the input random variables. $\mu, \sigma$ and cov represent the mean, the standard deviation and the coefficient of variation of the random variables, respectively

Other likely uncertainties as those related to cracking and crushing of concrete, strain hardening and ultimate strength of steel, effects such as slab participation or uncertainties related to the model options, can be also included in the probabilistic structural analysis. It is worth noting that, if new random variables were considered, they would affect both, dynamic and static results. In this article, the random variables mostly affecting the uncertainties of the response in an explicit way were considered. Nonetheless, notice that the uncertainties of several structural variables are taken into account indirectly as they are calculated as functions of the explicitly considered random variables. For instance, the elastic modulus of the concrete, 
$E c$, is related to fc by the equation $E c=4500 \sqrt{ } f_{c}$ and, for the calculation of the yield strength, $f y$, the expression $f y=0.0021 E s$ is used.

\subsection{Seismic hazard to perform IDA}

One of the most important sources of uncertainty, when estimating the seismic risk of structures, is the random variability of the ground-motion. Its influence has been studied by Bommer \& Crowley Bommer and Crowley 2006. The forecasting of the ground-motion parameters has been studied by Abrahamson et al. 1991, Bommer et al. 2007 and by Arroyo and Ordaz 2011. Having said that and according to the probabilistic simulation approach of this article, it is necessary to model the seismic hazard as a random variable. To do that, 10 earthquakes have been selected from the European database, Ambraseys et al. 2004, by using a criterion for controlling the dispersion of the data. Use is made of a method proposed by Vargas et.al. 2013a for obtaining a set of earthquake records from a database. Such records fit a target response spectrum, under a mean square metrics. The response spectral function selected in this study corresponds to the type 1 of the Eurocode 8 (EC8), CEN 2004, that has a surface-wave magnitude greater than 5.5. Several methods to establish the optimal number of accelerograms, required to perform the inelastic dynamic analyses, have been studied by Hancock et al. 2008 and they conclude that the exact number depends on the damage measures which are considered and also on their predictability. Most of these methods are based on the magnitude and on the spectral shape. Figure 2 depicts the spectra of the selected earthquakes, their average spectrum, and the target spectrum. In Figure 2 can be seen that the procedure used for selecting earthquake records allows a good fit. The list of these earthquakes and of their main characteristics are given in Table 3. 


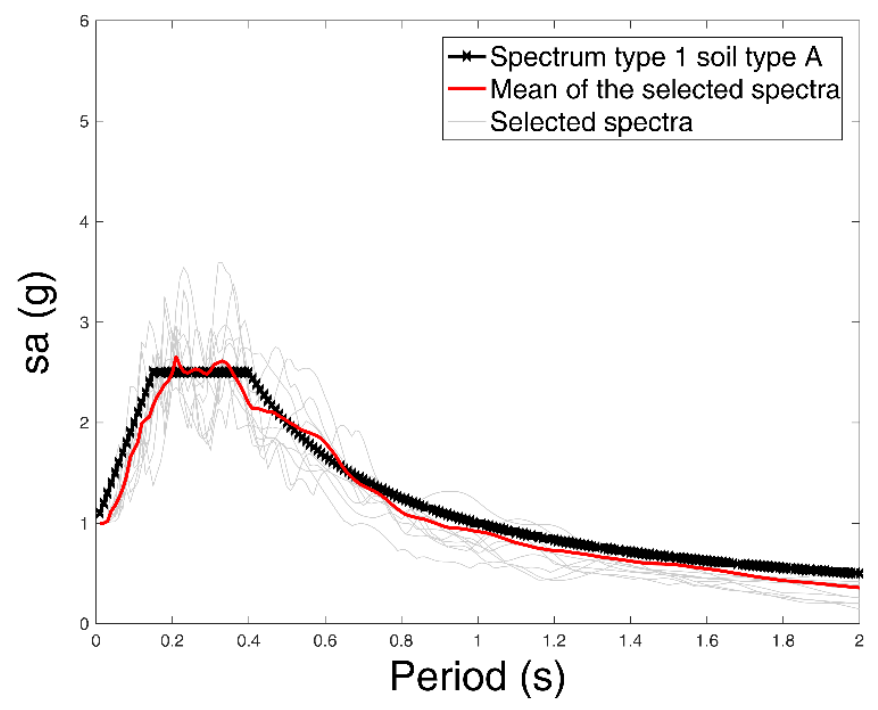

Figure 2 Response spectra calculated from the procedure based on the mean spectrum

The selection of the earthquake records according to the method proposed by Vargas et.al. 2013a is based on the mean squared error calculated between the mean of a group of response spectra, previously selected from a sorted database criterion, and the target spectrum function. The criterion for sorting the database is based on the mean squared errors between actual spectra and a target spectrum. The earthquake records are sorted according to such errors in ascending order; thus, the record whose response spectrum is the most similar to the target spectrum is ranked as the first one; and so on. It is worth noting that this selection procedure avoids the sensitivity of the method to single records, as the sorting procedure itself discards records leading to likely significant differences in the dynamic analyses as well as in the computations of the performance points. It was also found that the number of records that minimizes the error function as defined in Vargas et al. (2013a) takes values between 10 and 30. Ten records have been used to take into account the randomness of the seismic actions in this study. However, an anonymous reviewer noted that the way the seismic actions have been selected could underestimate the record-to-record variability, thus enhancing the variability in the response due to the randomness of the mechanical properties. Eads et al. (2013) quantified the uncertainty in the collapse fragility curves and mean annual frequency of collapse as a function of the number of ground motions used in calculations, showing that using a small number of 
ground motions can lead to unreliable estimates of a structure collapse risk. It is recognized the importance of this issue in seismic expected damage and seismic risk assessments and should be faced carefully in future research. The record selection method used here needs to be checked against other ground motion selection methods as, for instance the one proposed by Lin et al (2013).

\begin{tabular}{|c|c|c|c|c|c|c|c|}
\hline \multirow{2}{*}{$\begin{array}{l}\text { Station } \\
\text { name }\end{array}$} & \multirow{2}{*}{ Date } & \multicolumn{2}{|c|}{$\begin{array}{l}\text { Epicentre } \\
\text { (degrees) }\end{array}$} & \multirow{2}{*}{$\begin{array}{c}\text { Depth } \\
(\mathbf{k m})\end{array}$} & \multirow{2}{*}{$\begin{array}{l}\text { Magnitude } \\
\text { (Ms) }\end{array}$} & \multirow{2}{*}{$\begin{array}{c}\text { Local } \\
\text { geology }\end{array}$} & \multirow{2}{*}{$\begin{array}{c}\text { Epicentral } \\
\text { distance } \\
(\mathbf{k m})\end{array}$} \\
\hline & & $\mathrm{N}$ & $\mathrm{E}$ & & & & \\
\hline $\begin{array}{c}\text { Arquata del } \\
\text { Tronto }\end{array}$ & 19.09 .1979 & 42.76 & 13.02 & 4 & 5.84 & Rock & 22 \\
\hline San Rocco & 15.09 .1976 & 46.32 & 13.16 & 12 & 5.98 & Stiff soil & 17 \\
\hline $\begin{array}{c}\text { Kotor } \\
\text { NasRakit }\end{array}$ & 24.05 .1979 & 42.23 & 18.76 & 5 & 6.34 & Rock & 21 \\
\hline Auleta & 23.11 .1980 & 40.78 & 15.33 & 16 & 6.87 & Rock & 25 \\
\hline Ponte Corvo & 07.05 .1984 & 41.73 & 13.90 & 8 & 5.79 & Rock & 31 \\
\hline Matelica & 26.09 .1997 & 43.03 & 12.86 & 6 & 5.9 & Rock & 20 \\
\hline Tricarico & 05.05 .1990 & 40.65 & 15.92 & 12 & 5.6 & Rock & 20 \\
\hline $\begin{array}{l}\text { Izmit-M- } \\
\text { Istasyonu }\end{array}$ & 13.09 .1999 & 40.70 & 30.02 & 13 & 5.9 & Stiff soil & 13 \\
\hline $\begin{array}{c}\text { Bolu- } \\
\text { Bayindirlik }\end{array}$ & 12.11.1999 & 40.76 & 31.14 & 14 & 7.3 & Stiff soil & 39 \\
\hline $\begin{array}{l}\text { Athens- } \\
\text { Papagos }\end{array}$ & 07.09.1999 & 38.13 & 23.54 & 9 & 5.6 & Rock & 26 \\
\hline
\end{tabular}

Table 3 Main characteristics of the selected earthquakes.

$\mu_{\text {Depth }}=11 \mathrm{~km}, \sigma_{\text {Depth }}=3.8 \mathrm{~km}, \mu_{\mathrm{ED}}=22.9 \mathrm{~km}, \sigma_{\mathrm{ED}}=7.65 \mathrm{~km}, \mu_{\mathrm{Ms}}=6.13, \sigma_{\mathrm{Ms}}=0.55$

It is important to note that, in addition of finding earthquakes records compatible with a target spectrum, the method proposed by Vargas et.al. 2013a also has the ability to find and to select records corresponding to similar earthquake features, including depth and epicentral distance, local geology and size of the 
earthquakes, according to the great $\left(\mathrm{M}_{\mathrm{S}}>5.5\right)$ and moderate $\left(\mathrm{M}_{\mathrm{S}}<=5.5\right)$ earthquakes, as considered in Eurocode EC8. At the end of Table 3, statistics of these variables are shown. Mainly shallow great near earthquakes, recorded at rock or stiff soils, were automatically selected. Note also that dispersions around the central values are relatively small. Noticeably, this method for selecting the accelerograms also guarantees some record-to-record variability; in fact, for the entire range of periods, the coefficients of variation (cov) of the spectral acceleration values are in the range between 0.16 and 0.2 and, as no matching techniques are used, the frequency content, amplitudes and phases are retained. Lin et al (2013 a, b) analyzed the crucial problem of ground motion selection based on a target spectrum, concluding that the use of uniform hazard spectrum including variable uncertainties at different periods, results in overestimations of structural response hazard, whereas the conditional mean spectrum results in underestimation. Thus, the uncertainties due to seismic actions could be underestimated in this study.

\subsection{Probabilistic calculation based on IDA}

To take into account the uncertainties related to the variables described in Table 2, the Monte Carlo method is used. Nonetheless, an important issue related to the spatial variability should be treated before starting the calculation. It is well known that the spatial variability of the mechanical features of the structural elements may influence greatly the results, Franchin et al 2010. For instance, in order to consider the likely correlation that may exhibit the strength of concrete for the elements of a specific story, it is necessary to assume a correlation hypothesis between the random generated samples. Thus, it is supposed that the correlation between the strength of columns and beams of the same story decreases with distance. To do this, for the 2D frame depicted in Figure 1, the column of the first story numbered as $k=1$, will be the first from left to right, the column numbered as $k=2$, of the first story, will be the second one going from left to right and so on. Thus, the correlation matrix, $\rho_{i, j}$, for the concrete strength samples of one story is made in the following way: 


$$
\rho_{i, j}= \begin{cases}i=j & \rho_{i, j}=1 \\ i=j \pm k & \rho_{i, j}=1-\frac{k}{r}\end{cases}
$$

$\mathrm{r}$ is a coefficient associated to the level of correlation between adjacent elements. Further details of the hypothesis assumed to calculate the correlation matrix presented in equation 1 can be found in Vargas et al. 2017. Based on this correlation matrix, a group of correlated random samples can be generated for the concrete strength of columns of each story, while for each column of the same story, one independent random sample of the elastic modulus of the steel, Es, is assigned. The same criterion is used to generate random samples of the mechanical characteristics of the beams for each story. It is also important to note that groups of samples corresponding to different stories are independent. These considerations are based on the fact that usually structural elements of the same story are made of the same concrete but the properties of the reinforcement steel, from rebar to rebar, can be supposed as independent. It is also worth recalling that the aim of this article is related to the assessment of the expected seismic damage of individual buildings; nevertheless, this purpose could be extended to classes of existing structures in urban areas taking into account the building to building variation of the structural characteristics within a structural class. Further discussion on this issue can be found in Crowley et al. 2005.

Consequently, according to the spatial variability hypothesis presented, random samples of the mechanical properties of the materials are generated and, then, NLDAs are performed, for the earthquakes records linearly scaled. Because of the probabilistic approach, the fundamental period varies from building-tobuilding. Thus, the intensity measure (IM) selected for scaling the records has been the PGA. However, as also pointed out by one anonymous reviewer, other options could be feasible, or even, preferable. For instance, the spectral acceleration related to the mean period from all models of the Monte Carlo, or the period of the model having the mean (or median) parameter values could be good options for scaling the seismic records. However, to compare and discuss the influence of the different scaling options in probabilistic approaches requires additional work that falls beyond the main scope of this study. Therefore, 
PGA values from $0.05 \mathrm{~g}$ to $1 \mathrm{~g}$, at intervals of $0.05 \mathrm{~g}$, have been considered. The Latin Hypercube method is used to randomly combine earthquakes records and simulated buildings for performing NLDAs. 1000 NLDAs are performed for each PGA. In each analysis, the seismic global damage index of the building is obtained as a weighted mean of the damage indices initially estimated at structural element level. A brief description of the dynamic damage index employed in this research is given in the following.

\section{Damage index of Park and Ang}

Several damage indices for reinforced concrete elements, from a post-process of the nonlinear dynamic response, have been proposed in the literature, Williams and Sexminth, 1995. One of the most well established is the damage index of Park \& Ang, 1985, which is calculated as the sum of the maximum ductility divided by the ultimate ductility and a term related to the dissipated energy. In the case of the overall building, ductility is defined in terms of displacement but, for several structural members, ductility can be defined in terms of other parameters as, for instance, plastic rotation. The corresponding equation is:

$$
D I_{E}(\chi)=\frac{\mu_{m}(\chi)}{\mu_{u}}+\frac{\beta_{h} E_{h}(\chi)}{F_{y} \mu_{u} \delta_{y}}
$$

where $D I_{E}$ is the damage index at element level, $\chi$ is an independent variable, depending of the severity of the seismic action or, equivalently, of some parameter linked to the structural response. In this case, the PGA is used as the variable $\chi$. Other variables, such, for instance, roof displacement and/or spectral displacement, can be also used as $\chi$ variable. $\mu_{m}$ and $\mu_{u}$ are the maximum and ultimate ductilities, respectively; $\beta_{h}$ is a non-negative parameter, which represents the effect of cyclic loads on the structural damage. Taking into account the calibration of the Park and Ang damage index for reinforced concrete buildings, the $\beta_{h}$ value has been set to $0.05 ; E_{h}$ is the hysteretic energy dissipated; $F_{y}$ is the yield force and $\delta_{y}$ is the yield displacement. Then, the global damage index of the structure, $D I_{N L D A}$, is a weighted mean of 
the damaged elements, in which the weights are the ratio of the hysteretic energy dissipated by each element to the total hysteretic energy dissipated by the structure. The following equation describes this global damage index:

$$
D I_{N L D A}(\chi)=\sum_{i} \lambda_{i} D I_{E}(\chi)
$$

where $D I_{N L D A}(\chi)$ is the dynamic-analysis-based global damage index of the structure and $\lambda_{i}$ is the ratio of the dissipated hysteretic energy of an element $E$ to the dissipated hysteretic energy of the entire structure. It is worth recalling that the Park and Ang index provides a measure of the global damage of the structure by considering two sources of damage: the ductility reached for each structural element and the dissipated energy due to the hysteresis. The maximum ductility is related to the stiffness degradation, which is generally the main contributor to damage in reinforced concrete elements, but the contribution to damage of dissipated energy is also significant. Moreover, dissipated energy is probably the best way of taking into account the damaging effects of the earthquake duration.

Based on the results obtained by means of IDA, PDC relating the PGA to the damage index can be obtained. Figure 3a displays such PDC. According to the original calibration of the damage index made by Park \& Ang 1985, a damage index value equal or higher than 1 corresponds to the collapse of the structure. For this reason, when the damage index of Park and Ang is higher than 1, its value is set to 1. This makes sense, because, for higher PGAs, the standard deviation of the damage index decreases, what indicates that for higher PGAs the collapse uncertainty reduces. Notice that results presented in Figure 3a can be used to the estimation of failure probability functions or even fragility functions in terms of earthquake intensities. For instance, in Figure $3 \mathrm{~b}$ the fragility functions are presented by assuming that the damage states thresholds for slight, moderate, extensive and complete are $0.1,0.4,0.65$ and 1 , respectively. This assumption is based on the original calibration of the damage index, Park et al. 1985. 

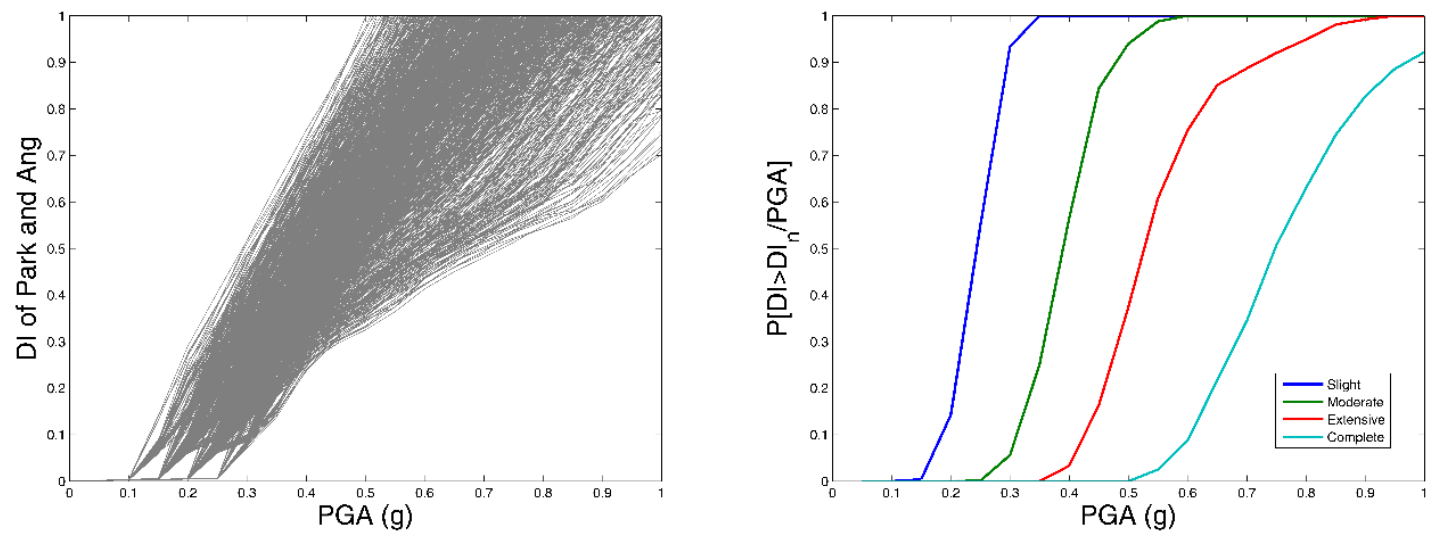

Figure 3 a) Damage indices of Park and Ang represented as a function of the PGA for the building shown in Figure 1 and b) fragility functions

To summarize the simulation scheme for calculating PDC based on IDA, a flow chart has been produced; it is shown in Figure 4. As mentioned above, seismic intensity is defined by PGA values in the range between 0.05 and $1 \mathrm{~g}$. Increments of $0.05 \mathrm{~g}$ are considered, so 20 PGA increasing values are used in the IDA. The following steps summarize the simulation scheme: step 1: generate a random structural model (counter $i, i=1: 100$ ); step 2: take the earthquake record of Table 3 corresponding to the iteration number (counter $j, j=1: 10$ ); step 3: increase the seismic intensity and scale the record to this PGA value (counter $k$, $k=1: 20)$; step 4: compute a NLDA and calculate the damage index of Park and Ang, $D I_{N L D A}$. Store the $D I_{N L D A}$ calculated in the matrix $M_{D Y N}(10 *(i-1)+j, k)=D I_{N L D A}$; check for intensity PGA; if the PGA is lower than the maximum PGA considered, go to step 3; else, check for record number; if the record number is lower than the maximum number of records considered, then go to step 2; else check for the $D I_{N L D A}$ statistical distribution; the convergence of the two first statistical moments of the distribution of $D I_{N L D A}$ is checked. If this convergence is unsatisfactory, then go to step 1; else end. It is worth noting that, in the present study, a number of 100 structural models together with 10 seismic actions warrants this convergence; thus, this last checking is avoided. 


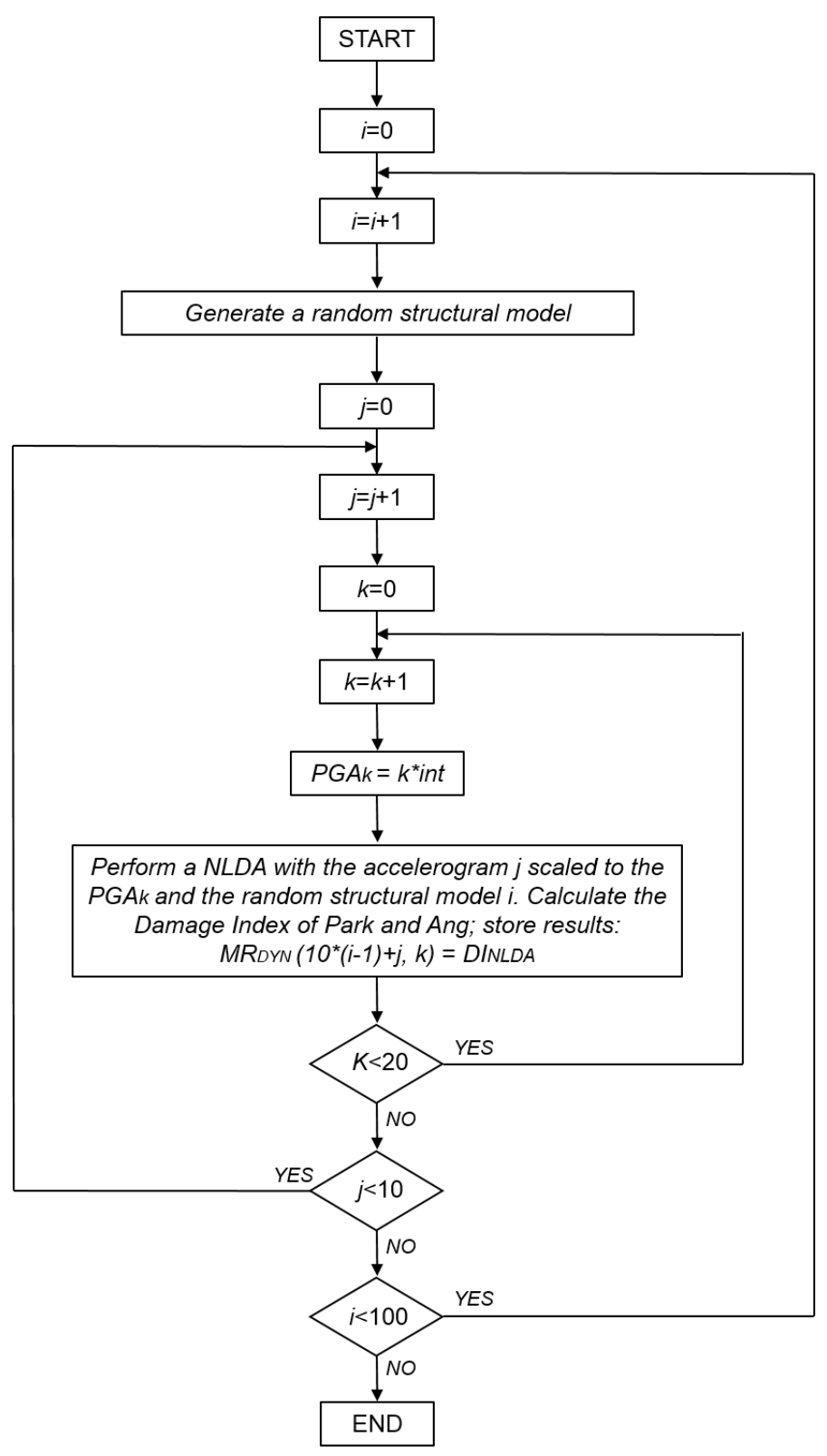

Figure 4 Flow chart of the simulation scheme for calculating probabilistic damage curves based on NLDA

\section{Damage index based on pushover analysis}

As mentioned above, when uncertainties of the material properties and of the seismic action are considered, IDA is an expensive computational way for obtaining PDC. Vargas et al. 2013a,b have shown a simplified procedure to obtain PDC based on the pushover analysis and fragility curves. However, this procedure does not allow to separate the damage into two components, like the damage index of Park and Ang approach. 
It is of high practical interest to develop a computationally less expensive procedure, based for instance on nonlinear static structural analysis, which allows obtaining PDC, similar to those calculated with the IDA method presented above. To do this, the incremental static analysis, that is, pushover analysis, PA, combined appropriately with an innovative procedure for estimating damage curves, Pujades et al. 2015, provides a powerful and simplified tool. To calibrate the pushover-based damage index, the global damage index of Park and Ang was selected because, as it will be shown below, both damage indices represent overall damage in the building. However, one must have in mind that the global index is a general indicator of the damage and that it is the result of a weighted average of the evolution of damage at a component level.

\subsection{Probabilistic Pushover Analysis}

The PA consists in applying a horizontal load to the structure according to a certain pattern of forces. This load value is increased until the structural collapse is reached. Afterwards, a curve relating the displacement at the roof to the base shear of the building is obtained. This curve is commonly known as capacity curve. Several researchers have shown the main advantages and disadvantages when PA methods are employed to calculate structural reliability estimates, Fragiadakis and Vamvatsikos 2010, Celarec and Dolšek 2013, Brozovič and Dolšek 2014. Notice that if the PA will be used in a probabilistic environment, several issues should be considered. In this way, Satyarno, proposed the adaptive pushover analysis, Satyarno 2000. An important advantage of the adaptive pushover is that the shape of the lateral load in each incremental load step is recalculated based on the first mode of vibration of the degraded structure. Besides, a Gordian knot in pushover analysis is to take a decision on the ultimate capacity point. Although several criterions exist, based on the decay of the maximum capacity, the adaptive pushover automatically ends pushing based on the stiffness degradation. Namely, when the eigen-frequency of the degraded structure is less than 10-6 times the initial elastic eigen-frequency, the method automatically stops incrementing the lateral load. In fact, it is assumed that a failure mechanism has occurred and that further increments would provide unrealistic values. These advantages are more important in probabilistic pushover analysis, because of the 
automatic solution of these two important concerns. Probably the main limitation of this procedure is the time consuming, as it requires evaluating the next pushing pattern in each iteration of the pushover analysis. A detailed description of this procedure can be found in the RUAUMOKO's manuals, Carr 2000. This structural program has been used in this study for calculating static and dynamic nonlinear structural analysis.

According to the values exposed in Table 1, 100 groups of Gaussian input data samples are generated, according to the correlation hypotheses exposed above (see section 2.4); then, the adaptive pushover analyses are performed. Figure 5 depicts the 100 capacity curves obtained which are characterized by random variables such as the elastic stiffness, the maximum displacement, the maximum base shear, etc. Notice that the 100 capacity curves shown in Figure 5 can be easily transformed into 100 capacity spectra, HAZUS 1999, ATC-40 1996. The right and top axes in Figure 5 serve for appreciating this transformation.

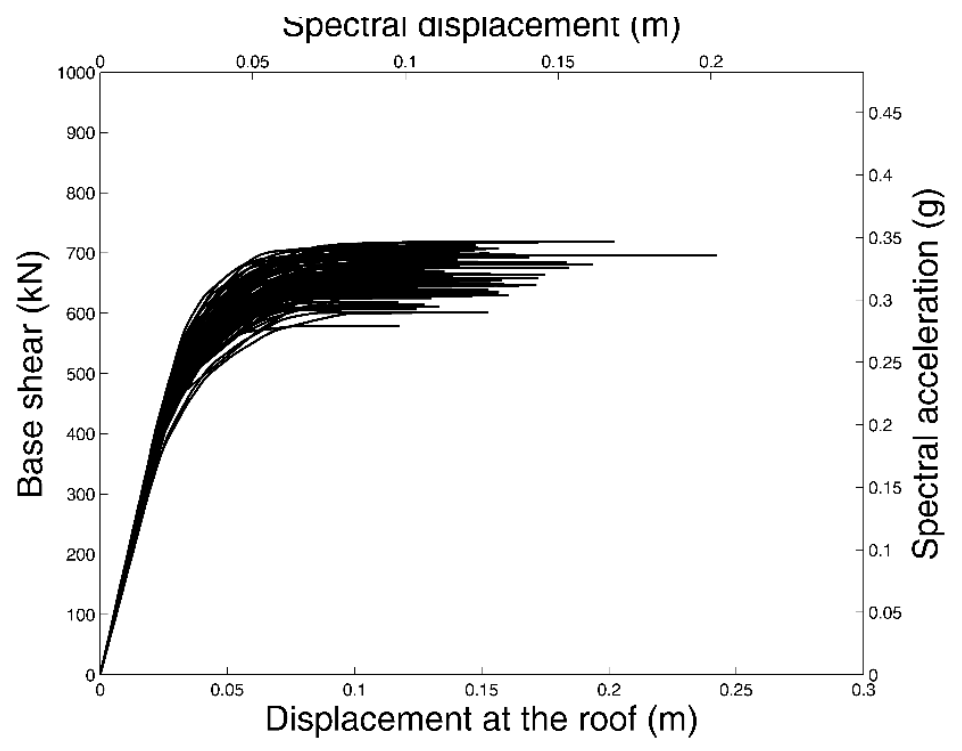

Figure 5 Capacity curves and capacity spectra of the building studied by considering the mechanical properties of the materials as random variables 


\subsection{Calculation of the performance points by considering uncertainties}

From a capacity spectrum of a structure and a response spectrum, there are several simplified methods to estimate the structural seismic response, HAZUS 1999, ATC-40 1996, FEMA 440 2005. These simplified methods generally look for obtaining the performance point. This latter is a measure of the expected demand of a structure. Thus, in order to calculate the performance point of the analyzed building, due to the same seismic hazard used in the IDA calculations, the response spectra of the earthquake records presented in Table 3 should be calculated. These response spectra, together with the capacity spectra depicted in Figure 5, are displayed in Figure 6. Obviously, the response spectra should be scaled to different intensity levels in the same way as in the IDA method. So, to facilitate the comparison of the results, the intensity levels will be the same ones that were used in the IDA calculations; that is, PGAs ranging from $0.05 \mathrm{~g}$ to $1 \mathrm{~g}$ at intervals of $0.05 \mathrm{~g}$. Figure 6 also shows an example of calculation of the performance points, for a PGA of 1g. In this figure the inelastic spectra, reduced due to the ductility of the building, are also shown. Note that the spectral displacement of the performance point is also referred to as target displacement in the international literature. The methodology applied for obtaining the performance point is further explained in FEMA 440.

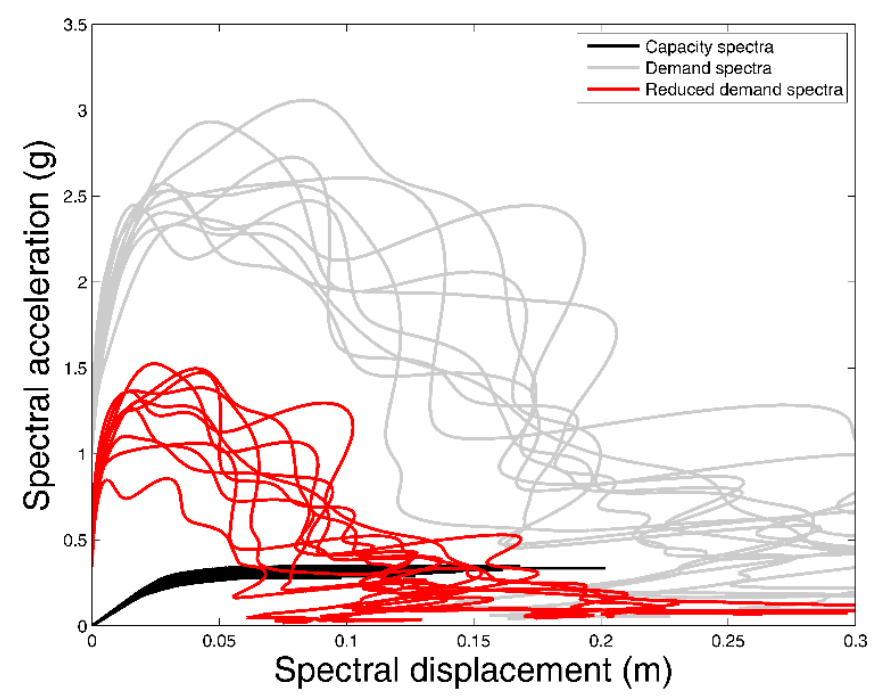


Figure 6 Performance point for a given demand and capacity spectra. The method applied is exposed in Chapter 6 of FEMA 440.

After computing all the performance points (20000 in this case), 1000 curves relating PGAs and the spectral displacements of the performance points are obtained. Figure 7 displays these curves, which will be useful to easily combine the uncertainties related to the mechanical properties of the materials and those related to the seismic hazard.

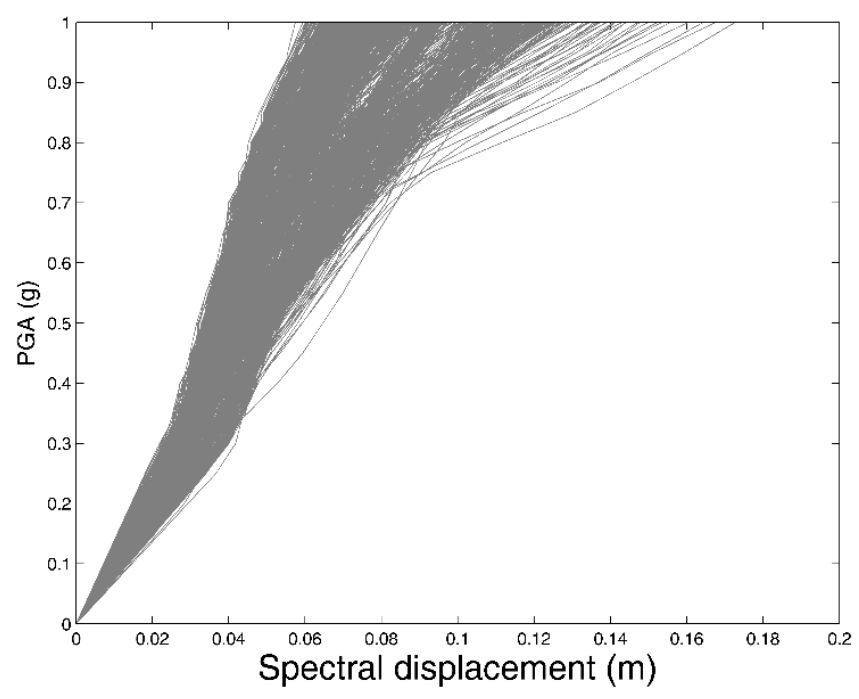

Figure 7 Relation between PGA to spectral displacement

To summarize the simulation scheme for calculating the curves of Figure 7, a flow chart is depicted in Figure 8 . The main steps of the proposed approach are as follows: step 1: a capacity curve is computed for a randomly generated structural model (counter $i, i=1: 100$ ); step 2: take the response spectrum of the record of Table 3 corresponding to the iteration number (counter $j, j=1: 10$ ); step 3 : increase the seismic intensity and scale the spectrum to this PGA value (counter $k, k=1: 20$ ); step 4: compute the performance point and store the spectral displacement of the performance point, $S d_{P P}$, in the matrix $M R_{S d-P G A}(10 *(i-1)+j, k)=S d_{P P}$; check for intensity PGA; if the PGA is lower than the maximum PGA considered, go to step 3; else, check for record number; if the record number is lower than the maximum number of records considered, then go 
to step 2; else check for the $S d_{P P}$ statistical distribution; the convergence of the two first statistical moments of the distribution of $S d_{P P}$ is checked. If this convergence is unsatisfactory, then go to step 1; else end. It is worth noting that a number of 100 structural models together with 10 seismic actions warranties this convergence; thus, this last checking is avoided.

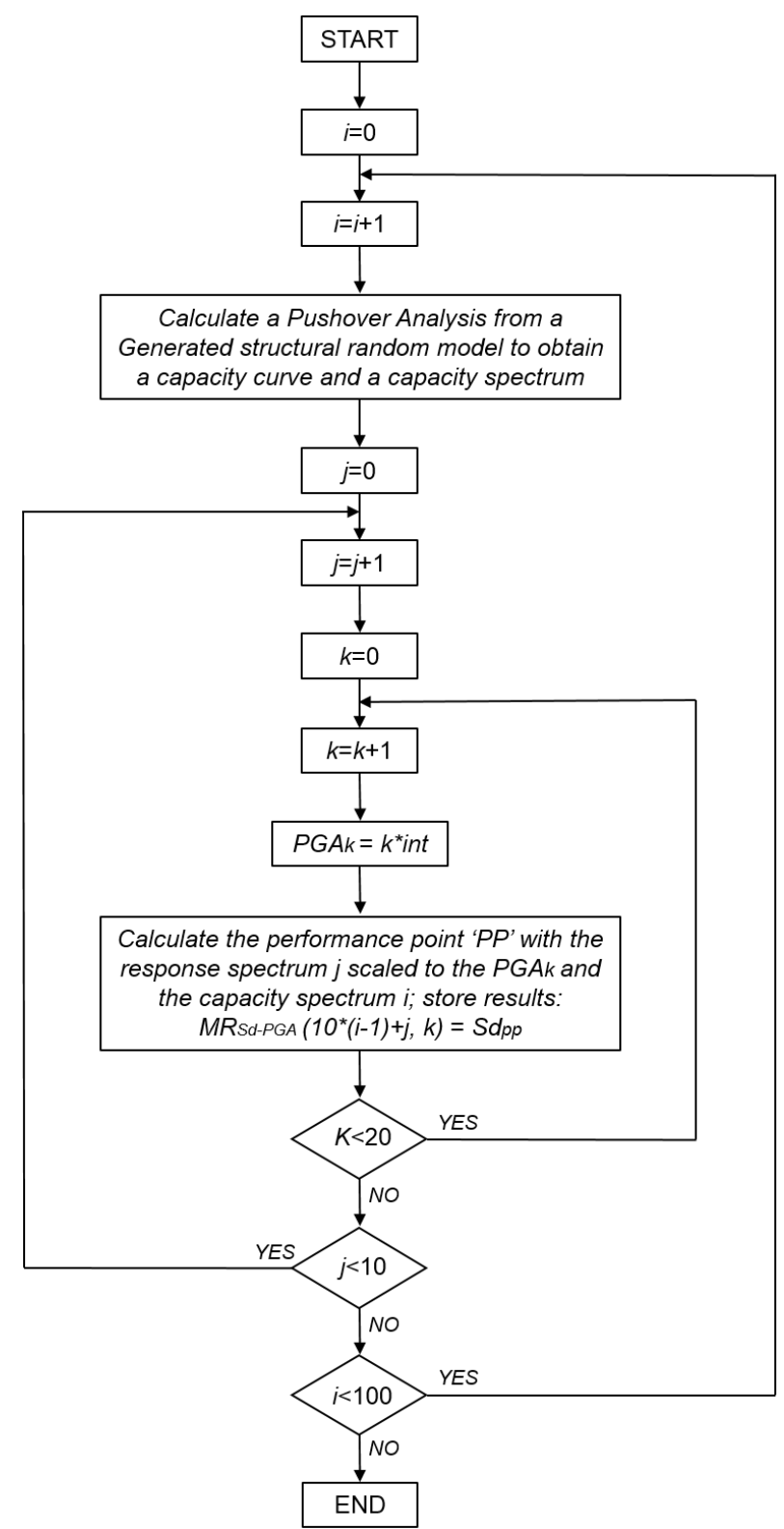

Figure 8 Flow chart of the simulation scheme for calculating capacity curves and the performance point ' $P P$ ' by considering the response spectra for the earthquakes records shown in Table 3 


\subsection{Calculation of the new simplified damage index}

As said above, the Park and Ang damage index is the sum of the contributions to damage of the maximum ductility and of the energy dissipated by the structural elements. Pujades et al. 2015 proposed an analogue equation for estimating a seismic damage index based on the PA:

$$
D I_{P A}(S d)=\alpha D I_{\mu}(S d)+\beta D I_{D E}(S d)
$$

in this equation, $D I_{P A}(S d)$ is the pushover-analysis-based global damage index of the structure; $\alpha$ is a coefficient that weights the contribution to the global damage of the first term of $D I_{P A}(S d)$ related to the ductility; $D I_{\mu}(S d)$ is the damage term related to the ductility; $\beta$ is a coefficient that weights the contribution to the global damage of the second term of $D I_{P A}(S d)$; and $D I_{D E}(S d)$ is the damage term related to the dissipated energy.

To obtain two functions from the capacity spectrum, to represent adequately the terms of equation 4 , it is necessary to analyze the tangent and secant stiffness functions as well as the dissipated energy curve; as it will be seen further on, these curves are obtained easily from the capacity spectrum. As shown above, the first term of the equation of Park and Ang (see eq. 2) is related to the maximum ductility reached by a structural element and it can be related to the stiffness degradation of the building. In the case of the capacity spectrum method, the first derivative of the capacity spectrum is directly related to the stiffness degradation. However, two kind of stiffness degradation can be calculated: the first one based on the tangent stiffness and the second one on the secant stiffness. Figure 9a shows the tangent and secant stiffness of the capacity spectra depicted in Figure 5. These stiffness functions can be transformed into a damage index based on the tangent stiffness or into a damage index based on the secant stiffness by means of the following equations (see Figure 9b):

$$
D I_{T S}(S d)=\frac{k_{e}-k_{t}(S d)}{\max \left(k_{e}-k_{t}(S d)\right)}
$$




$$
D I_{S S}(S d)=\frac{k_{e}-k_{S}(S d)}{\max \left(k_{e}-k_{S}(S d)\right)}
$$

In these equations, $D I_{T S}(S d)$ is the damage index based on the tangent stiffness; $k_{e}$ is the elastic stiffness; $k_{t}(S d)$ is the tangent stiffness; $D I_{S S}(S d)$ is the damage index based on the secant stiffness; and $k_{s}(S d)$ is the secant stiffness. Observe that both, $D I_{T S}(S d)$ and $D I_{S S}(S d)$, have been normalized by $\max \left(k_{e}-k_{t}(S d)\right)$ and $\max \left(k_{e}-k_{S}(S d)\right)$, respectively, in such a way that their highest value are 1.
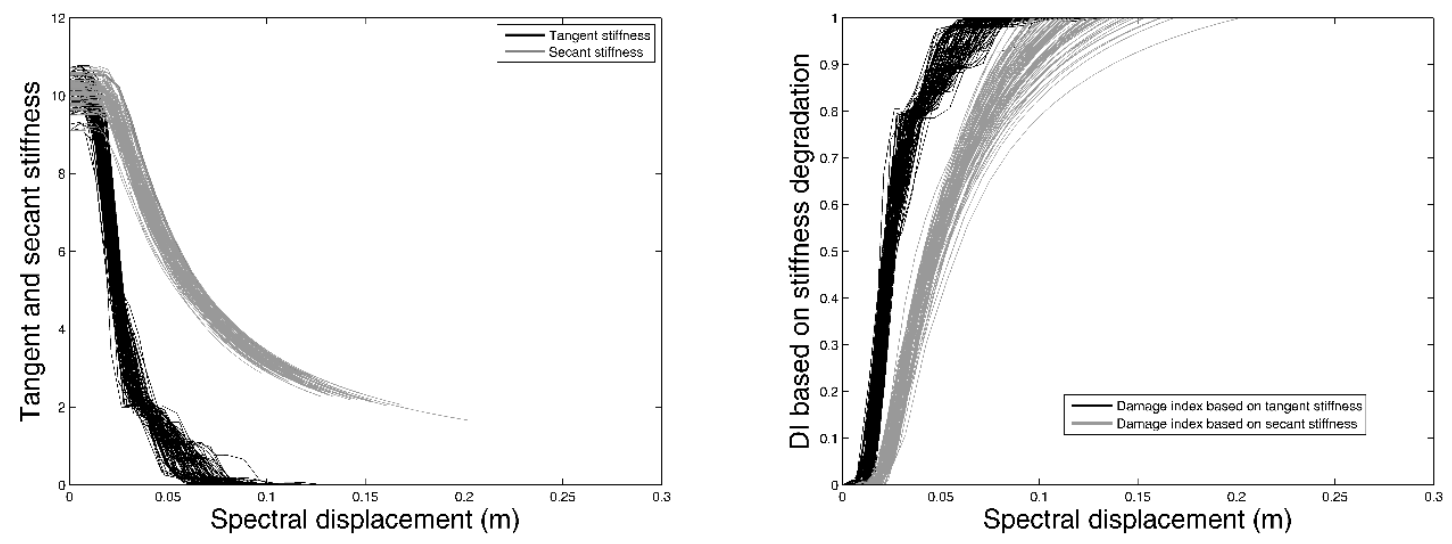

Figure 9 Tangent stiffness and secant stiffness of the capacity spectrum

The next step consists in selecting which of the calculated stiffness, tangent or secant, is a better candidate to represent the first term of Equation 4. If the first term of the Park and Ang equation is analyzed in detail, one can see that the maximum ductility reached during the time history response is normalized by the ultimate ductility. This fact indicates that the rate of evolution of the ductility index is closer related to the secant stiffness than to the tangent stiffness. Besides, the curves of Figure 5 do not show strong and sudden losses of stiffness. The later behavior can be likely in rigid structures, for which it can be expected that a combination of the tangent and the secant stiffness should be considered. For instance, if the infill walls were modelled nonlinearly would certainly lead to sudden losses of stiffness and strength and, probably, a linear combination between the secant and the tangent stiffness will be a better option for the first term of equation 4. Further research on this issue will allow generalizing equation 4, for new structural typologies. 
However, as pointed out above, for the building types considered in this article, it is expected that the major contribution to damage be due to secant stiffness degradation. Thus, the damage index based on the secant stiffness has been selected as the first term of Equation 4, i.e., $D I_{\mu}(S d)=D I_{S S}(S d)$.

The second term of the proposed damage index in equation 4 stands for the dissipated energy as a function of the spectral displacement. This term is obtained as the cumulative integral of the nonlinear part of the capacity curve as defined in Pujades et al. 2015. This cumulative integral also can be easily obtained by integrating the function defined as the subtraction of the capacity curve, $S a(S d)$, from a projected line of the elastic part of the capacity spectrum. Then, this energy-based index is normalized so that its value at the ultimate capacity point is one. Thereby, this index holds for the relative energy dissipated as referred to the energy loss at the ultimate or collapse point. The following equation is used to compute this energy term and Figure 10 illustrates the meaning of the involved functions and areas.

$$
D I_{D E}(S d)=\frac{\int_{\xi=0}^{\xi=S d}(k e * \xi-S a(\xi)) d \xi}{\max \left[\int_{\xi=0}^{\xi=S d}(k e * \xi-S a(\xi)) d \xi\right]}
$$

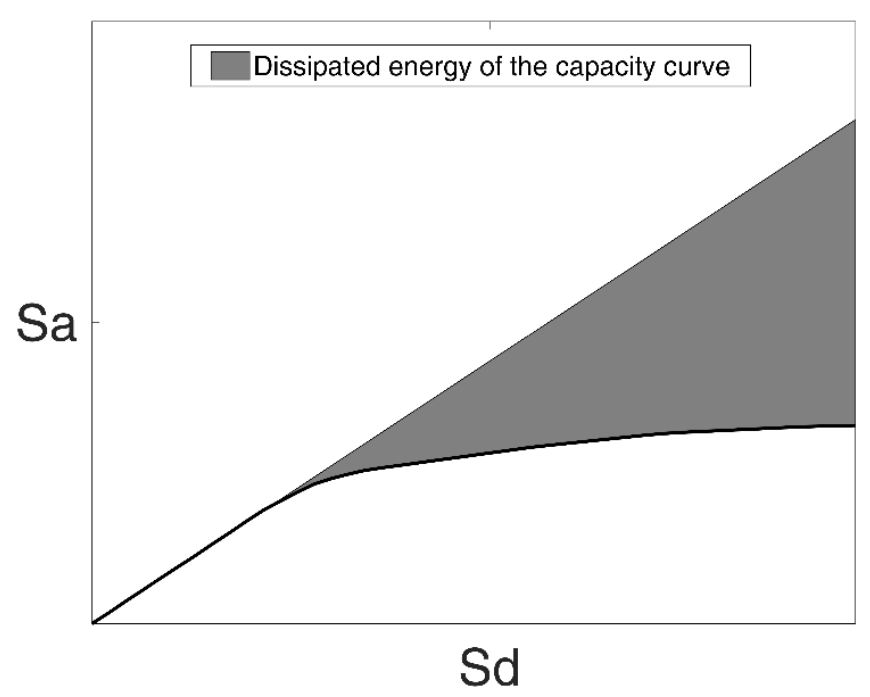

Figure 10 Graph depicting the functions and areas involved in the definition of the Energy term in equation (4) as described above and formulated in equation (7) 
Figure 11 depicts both terms of Equation $4, D I_{\mu}(S d)$ and $D I_{D E}(S d)$.

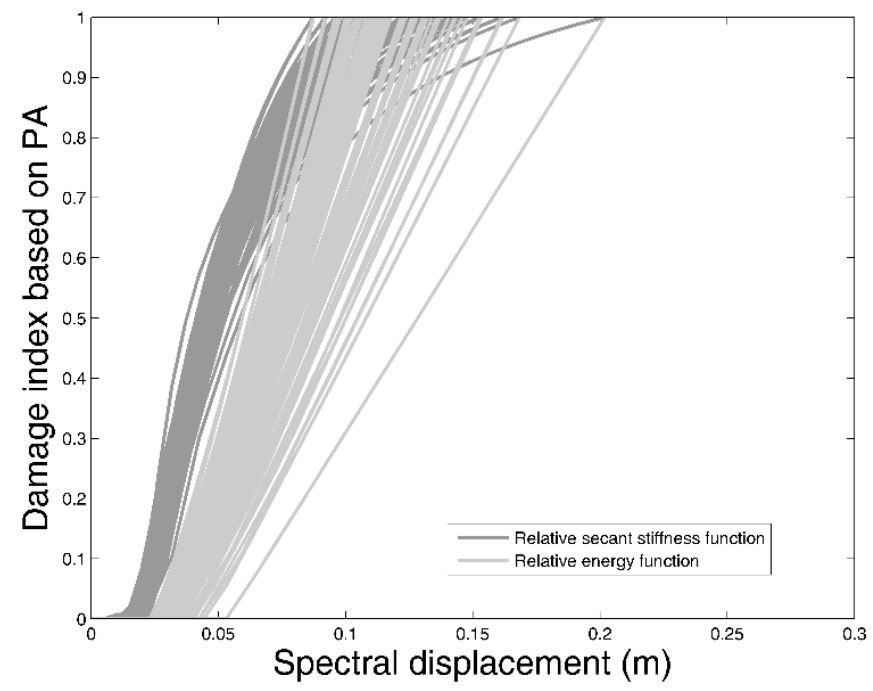

Figure 11 Stiffness and energy functions for calculating the new damage index.

According to Equation 4, the coefficient $\alpha$ and $\beta$ are weights of the damage terms related to the ductility and energy functions, respectively. However, it is important to recall that, in this paper, the values of the Park and Ang damage index, when larger than 1 were set to 1. Pujades et.al 2015 proposed the following assumption to avoid that the values of the new damage index be larger than 1:

$$
\alpha=1-\beta
$$

Therefore, equation 8 allows rewriting Equation 4 as follows:

$$
D I_{P A}(S d)=\alpha D I_{\mu}(S d)+(1-\alpha) D I_{D E}(S d)
$$

If equation 9 is applied for $\alpha=0.5$, the curves shown in Figure 12 are obtained. 


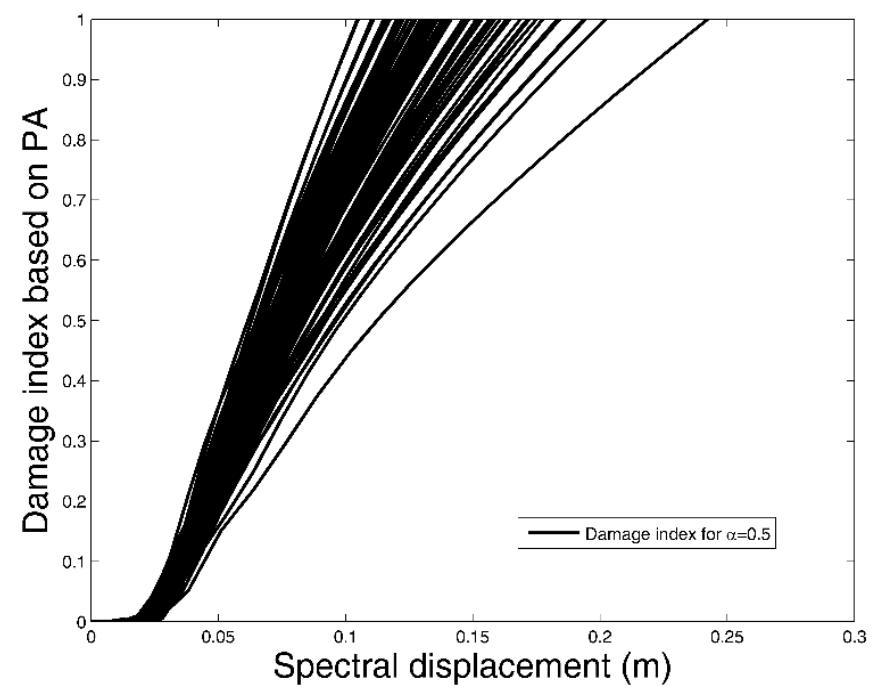

Figure 12 New damage index for $\alpha=0.5$.

However, these curves do not take into account the seismic action yet. Thus, to take account of it, a change of variable is performed by transforming the spectral displacement into a parameter explicitly linked to the seismic hazard as, for instance, PGA. It is important to recall that 1000 curves, connecting PGA and spectral displacement for the building and the seismic actions, were shown in Figure 7. These functions allow making the appropriate change of variable, as each of these curves were obtained by calculating the performance points in an incremental way. Then, the new damage index can be expressed as a function of the peak ground acceleration, PGA. It is important to note that these performance point computations have been made by using the same PGA values that were used in the nonlinear dynamic analysis.

In Figure 13, the PDC calculated by using IDA are compared with the probabilistic damage curves, calculated by using PA, for an $\alpha=0.7$. 


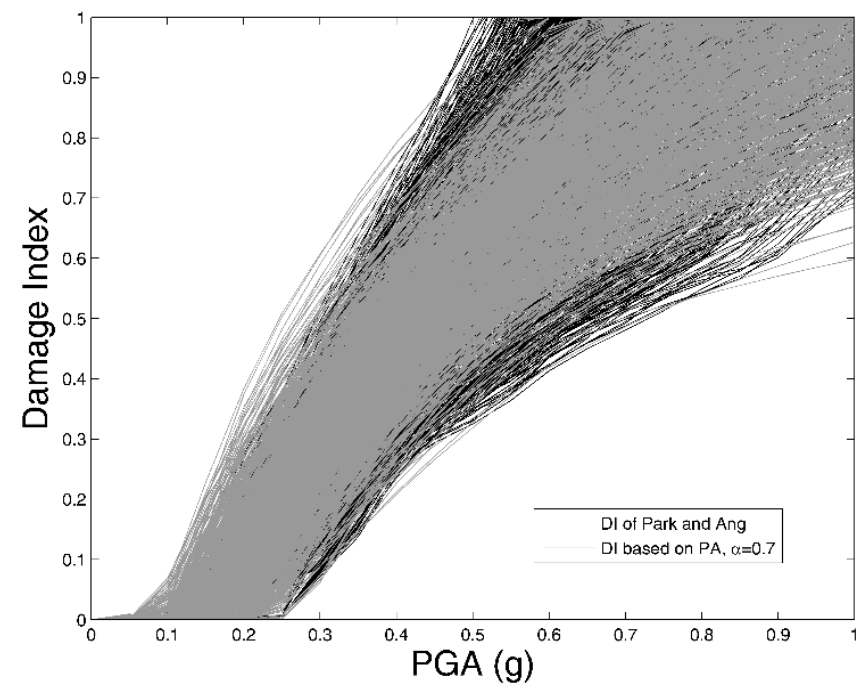

Figure 13 Comparison between damage indices by using IDA and PA

Even if this comparison seems to exhibit a relatively good fit among the Park and Ang damage index and the proposed one, important differences appear when likening the percentiles of each group of PDC. In order to obtain a coefficient $\alpha$, which provides the best fit between the curves obtained via IDA and PA, the Mean Squared Errors (MSE) for percentiles 5, 50 and 95 are calculated for a suite of $\alpha$ values. Figure 14 shows the evolution of the MSE with $\alpha$, for each percentile. $\alpha$ values go from 0 to 1 , with increments of 0.01 .

Figure 15 shows the comparison between the curves obtained by using IDA and PA approaches for percentiles 5, 50 and 95 . The best fit is obtained by using $\alpha=0.65, \alpha=0.78$ and $\alpha=0.67$ for percentiles 5, 50 and 95, respectively. It is important to observe the good adjust exhibited by the curves calculated with both methods. This fact demonstrates the validity of the simplified proposed approach based on PA. 


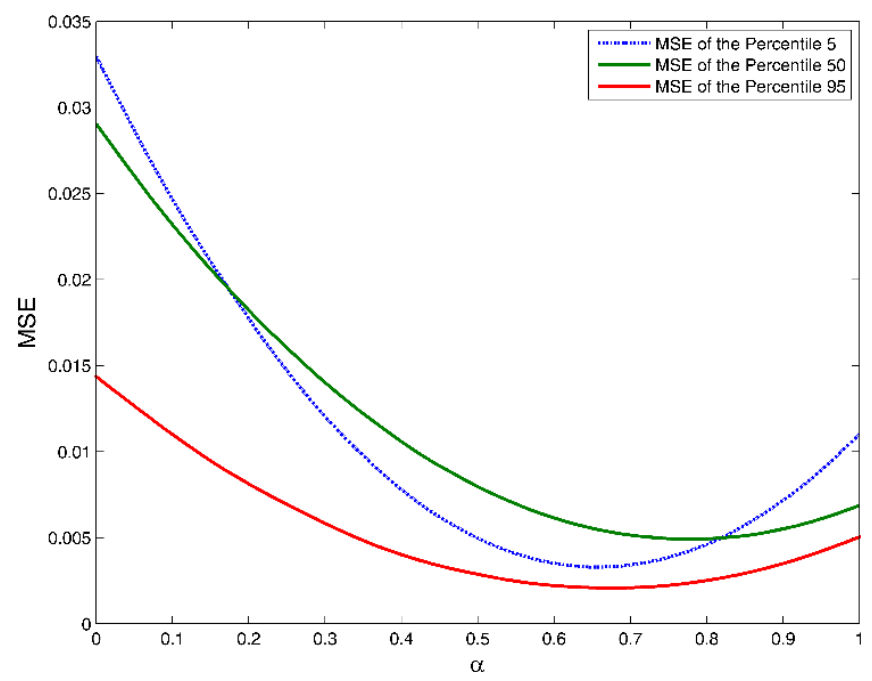

Figure 14 Mean squared error for percentiles 5, 50 and 95 as a function of $\alpha$

However, it is also true that $\alpha$ is an important parameter and that its value is critical to calculate the new damage index. Thus, a key issue concerning to this new damage index, is that parameter $\alpha$ is calibrated on the basis of the Park and Ang index. Indeed, this parameter is selected using a criterion based on the error with respect to the reference solution. So, the advantage of the new procedure seems to fade away. Moreover, one would expect that this error should not be always available, particularly for involved structural systems. Thus, the usefulness and success of the simplified method in practical applications seems also debatable. That would be true if very different $\alpha$ values were obtained in different applications, but the values found herein for framed reinforced concrete structures have shown to be very stable, with minor variations. For instance, Diaz-Alvarado et al. 2017 have recently found $\alpha$ values of $0.71,0.66$ and 0.67 respectively for low-, mid- and high-rise frame steel buildings, using earthquakes recorded in soft soils of Mexico City, that have long durations. Thus, such stability of the parameter $\alpha$ is a stronghold of the method. In this paper, only the fundamentals of the method have been shown but, ongoing work is being done in order to provide tabulated $\alpha$ values for typical housing buildings including low- mid- and high- rise, unreinforced masonry, reinforced concrete and steel buildings, typical of the European cities and towns. Besides, $\alpha$ values are being calibrated for seismic actions compatible with several response spectra. Thus, 
damage curves might be obtained, in a fast and straightforward way, for several buildings typologies and seismic hazards. Moreover, the versatility of this new damage index, also allows providing adequate corrective factors for different kinds of seismic actions and/or for different types of soils. The use of these factors would improve the accuracy of the new damage functions. Moreover, conservative $\alpha$ values can be taken for required or predefined confidence levels. However, it also must be said that the calibration of this parameter $\alpha$ for irregular or involved buildings and structural systems would not be simple.
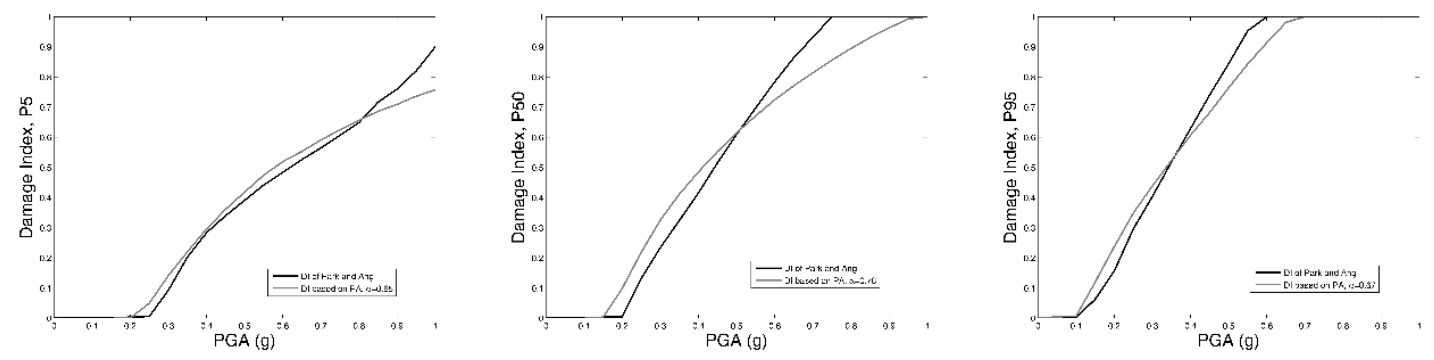

Figure 15 Comparison between percentile 5, 50 and 95 of the damage indices by using IDA and PA. For these cases $\alpha$ values are $0.65,0.78$ and 0.67 respectively for 5,50 and 95 percentiles

Anyhow, Figure 15 highlights the fact that the proposed method allows reproducing, in a simple and straightforward way, the results obtained by using more sophisticated stochastic nonlinear dynamic analysis. Moreover, the computational effort is much lower, due to the simple single-degree-of-freedom approaches involved and also to the easy computation of the performance point.

Finally, Figure 16 shows a flow chart, depicting the main steps involved in the computation of the new capacity-based damage indices. Please recall, at this point, that 100 capacity curves (counter 1) have been already obtained and stored. Moreover, for each capacity curve, $10 S d$-PGA curves (counter 2) are also available, $S d$ holds for the spectral displacement of the performance point. 


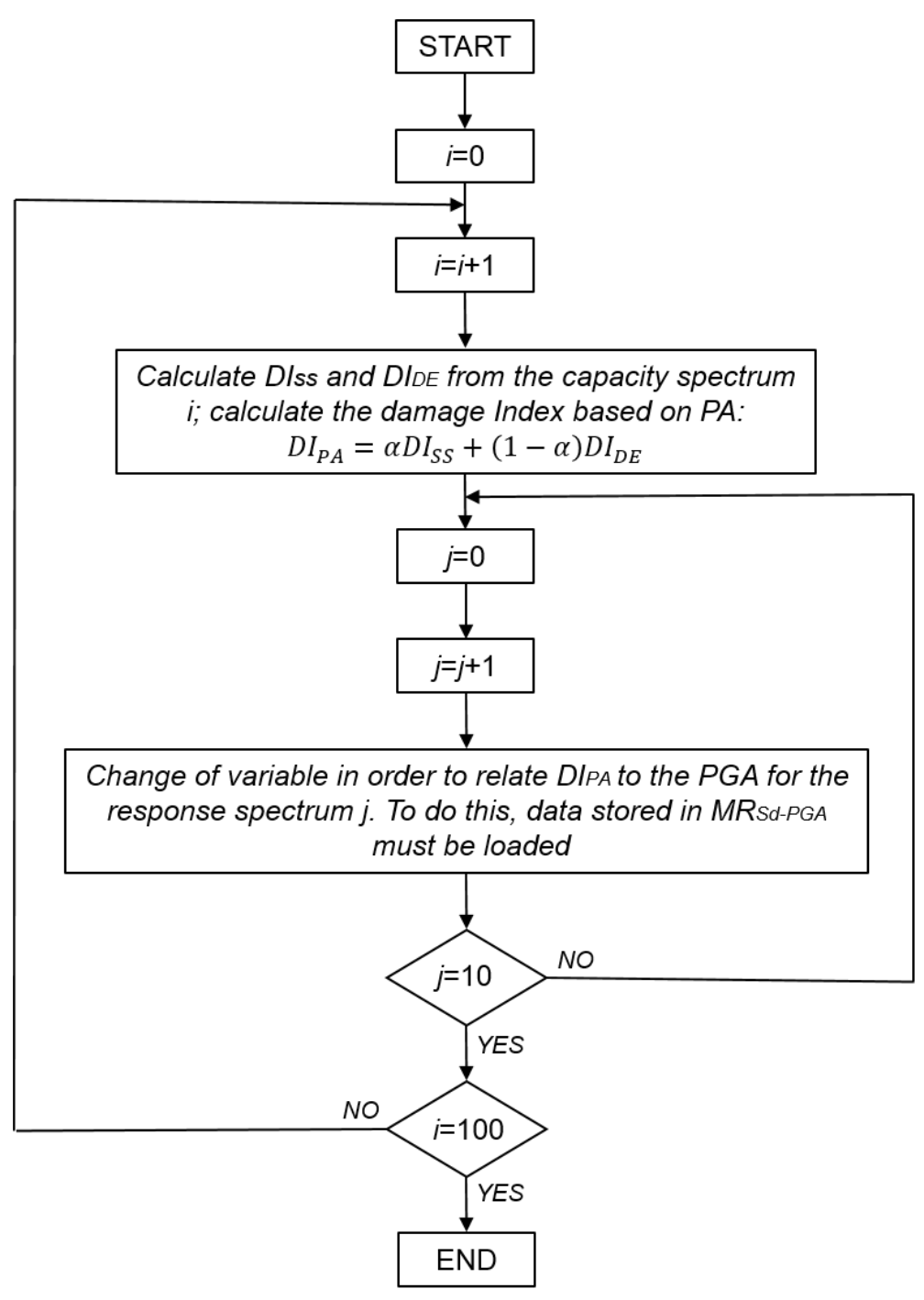

Figure 16 Flow chart depicting the computation of the capacity-based damage index as a function of the PGA. (See also explanations in the text).

Then, there is a curve for each earthquake record, each curve having 20 points corresponding to 20 intensity levels; that is, $1000 S d$-PGA curves have been also computed and stored previously in the $M R_{S d-P G A}$ matrix. These 1000 curves have been shown already in Figure 7. Then, for an assumed value of $\alpha$, the steps to obtain the new damage index as a function of PGA, are summarized as follows: step1: for each capacity curve (counter 1), compute stiffness and energy functions according to equations (6) and (7) and combine them according to the assumed $\alpha$ value; a damage index as a function of the $S d$ is obtained. Step 2: for each 
earthquake record (counter 2) load the corresponding $S d$-PGA curve from the $M R_{S d-P G A}$ matrix. This way, a damage index as a function of the PGA is obtained (these curves for a $\alpha$ value of 0.5 have been shown in Figure 13). Check for the number of records and for the number of buildings; if the maximum number of records (10 in this case) has not been reached, then go to step 2 again; else if the maximum number of structures has not been got, go to step 1; else end.

\section{Discussion of the proposed approach}

From a numerical point of view, the main advantage of the proposed method lies on the computational cost. In fact, given a structural model and a seismic action, defined by an earthquake record, the static analysis requires computing: i) the capacity spectrum, ii) the elastic response spectrum of the record and iii) crossing capacity and response spectrum to get the performance point. Crossing capacity and response spectrum is a quick and straightforward process. Obtaining the response spectrum implies to integrate the equations of motion of a single-degree-of-freedom linear system defined by means of the period and damping. The obtaining of capacity spectrum is the most demanding part of the simplified method. Typically, the overall PA for the building analyzed herein, including the computation of the capacity curve and of the performance point on a i7 $3 \mathrm{GHz}$ processor, takes no more than $240 \mathrm{~s}$. Taking into account that obtaining a complete damage curve requires to estimate 20 times the performance point, but that this calculation does not require the computation neither of the capacity curve nor of the response spectrum, the overall time for a single damage curve by means of static analysis is no more than 400 s. Otherwise, nonlinear dynamic analyses require solving the motion equations of a multi-degree-of-freedom nonlinear system at each point of the record, which typically is described by means of several thousands of time-acceleration pairs. Assuming a $30 \mathrm{~s}$ bracketed duration or about 3000 time-acceleration pairs, typical computation times for a single dynamic analysis of the same structure, on an $17-3 \mathrm{GHz}$ processor, are about $120 \mathrm{~s}$. Moreover, it must take into account that the dynamic analysis must be done for each one of the scaled records, 20 in the present case; so that; overall computation time may be about $2400 \mathrm{~s}$; that is, about 6 times the computational cost 
of the PA-based-method. Note that this difference between the numerical costs increases when the number of seismic intensities involved in the incremental dynamic analysis does.

Moreover, the fact that many computations can be done in an independent manner for different seismic actions and for different random structures, makes the procedure parallelizable in an easy way; although this is also true for nonlinear dynamic analyses. Notice that, special care must be put into the design and programming of the routine or function used to compute the performance point, by crossing capacity and demand spectra. Actually, the fact that response spectra of actual records are noisy functions may complicate the finding of the performance point, leading to a potential bottleneck of the procedure. However, smoothing the response spectra improves the numerical calculation of the performance point.

\section{Conclusions}

The main objective of the present article was to develop a simplified method for obtaining probabilistic damage curves of structures based on the pushover analysis. As a testbed, the physical damage of a framed reinforced concrete building has been assessed, taking into account that the input variables are random. Not only the strength of the concrete, the elastic modulus of the steel and other related mechanical properties have been treated as random variables, but also the seismic action has been considered in a stochastic way. An important conclusion is that the results presented herein show significant uncertainties in the seismic response and expected damage, when taking into account the randomness of the input variables. With the objective of improving the damage analysis, a new procedure has been presented. It is based on the stiffness degradation and on the energy loss. The results calculated by using this new approach show a very good agreement with the results obtained by means of dynamic analysis.

One of the most relevant conclusions of this work is that, when the procedures discussed herein are used to evaluate the expected seismic damage of a structure, the parameters influencing upon the seismic damage curves of the structures must be considered as random. Simplified deterministic procedures based on 
characteristic values, usually may lead to conservative results. Nevertheless, some abridged assumptions on the definition of the seismic actions and on the estimation of the seismic damage states and thresholds can also underestimate the real damage that can occur in a structure.

A structural typology, which can be classified as a low-to-mid-rise symmetric reinforced concrete framed building was studied. The results are compared, from a probabilistic perspective, with the damage curves calculated with IDA, in terms of several percentiles. The results clearly show the good fit of the damage curves calculated with the new method. However, so far, the proposed method has been applied only to simplified symmetric models, where the first mode of vibration dominates the seismic response and for which, 2D models are enough to capture the structural response. For tall, irregular or asymmetric buildings, further considerations should be made by taking into account higher modes effects in elevation, Chopra et al. 2004, Poursha et al. 2009, in plan, Chopra and Goel 2004, Bento et al 2010, Reyes and Chopra 2010, or in both, plan and elevation, Kreslin and Fajfar 2012, Reyes and Chopra, 2010, Reyes and Chopra, 2011, Fujii 2011, among other aspects. In these cases, the influence of higher modes should be reviewed and considered in order to enhance the scope of the proposed method.

A parameter named $\alpha$ was used to weight the contribution to the global damage due to the ductility and the dissipated energy. Really, this parameter depends on the structure, but also on the seismic actions. Probably this is a strong point of the capacity-based damage index because of its versatility and robustness. Ongoing research indicate that brittle structures submitted to impulsive seismic actions lead to $\alpha$ values slightly higher than 0.8 . On the contrary, ductile structures submitted to long duration intense signals produce lower $\alpha$ values, thus indicating that a significant contribution to damage comes from energy dissipation. However, the range of variation of $\alpha$ is narrow; values in the range $\sim 0.65-0.9$ have been generally found. This fact demonstrates the stability and, at the same time, the versatility of the capacity-based damage index.

Because the purpose of this study is not related to any specific site, the target spectrum has not been linked to probabilistic seismic hazard analyses. Moreover, simplified methods have been used to select and to 
scale strong ground motions to perform the comparison between the results of the nonlinear static and dynamic analyses. However, it is recognized that more realistic target spectra and more sophisticated scaling methods, should be investigated in order to analyse and discuss the results in specific sites where PSHA results are available.

Finally, several advantages of the new method are summarized as follows: 1) the computational effort is much lower than the required by IDA. To be precise, at least a reduction to one sixth of the computational effort was observed when using the new procedure; 2) if the seismic hazard changes, the dynamic analysis requires to perform new complete nonlinear dynamic structural analyses, while the new procedure only requires to compute the new performance points as the capacity curve simply depends on the structure; 3 ) the new method also allows to take into account the uncertainties of the structural behavior and the ones of the seismic actions.

\section{Acknowledgements}

This research has been partially funded by the Ministry of Economy and Competitiveness (MINECO) of the Spanish Government and by the European Regional Development Fund (FEDER) of the European Union (UE) through projects referenced as: CGL2011-23621 and CGL2015-65913 -P (MINECO / FEDER, $\mathrm{UE})$.

\section{References}

Ambraseys, N., Smit, P., Sigbjornsson, R., Suhadolc, P. and Margaris B. Internet-Site for European Strong-Motion Data, European Commission, Research-Directorate General, Environment and Climate Programme. http://www.isesd.hi.is/ESD Local/frameset.htm [22 may 2017].

Arroyo, D. and Ordaz, M. On the Forecasting of Ground-Motion Parameters for Probabilistic Seismic Hazard Analysis. Earthquake Spectra, 2011; 27(1), 1-21. 
ATC-40. Seismic evaluation and retrofit of concrete buildings. Applied Technology Council, Redwood City, California 1996.

Barbat, A.H., Carreño, M.L., Cardona O.D. and Marulanda, M.C. Evaluación holística del riesgo sísmico en zonas urbanas. Revista internacional de métodos numéricos para cálculo y diseño en ingeniería, 2011; 27(1), 3-27.

Bento, R., Bhatt, C. and Pinho, R. Using nonlinear static procedures for seismic assessment of the 3D irregular SPEAR building. Earthquake and structures, 2010; 1(2), 177-195.

Bhatt, C., Bento, R. Assessing the seismic response of existing RC building using the extended N2 method. Bulletin of Earthquake Engineering, 2011; 9(4), 1183-1201.

Bommer, J.J. and Crowley, H. The influence of ground motion variability in earthquake loss modelling. Bulletin of Earthquake Engineering, 2006; 4(3), 231-248.

Abrahamson, N.A., Somerville, P.G. and Cornell CA. Uncertainty in numerical ground motion predictions. Proc. $4^{\text {st }}$ U.S. National Conference of Earthquake Engineering. EERI,1991; 407-416.

Bommer, J.J., Stafford, P.J., Alarcón, J.E., Akkar, S. The influence of magnitude range on empirical ground-motion prediction. Bulletin of Seismological Society of America, 2007; 97(6), 2152-2170.

Brozovič, M. and Dolšek, M. Envelope-based pushover analysis procedure for the approximate seismic response analysis of buildings. Earthquake Engineering and Structural Dynamics, 2014; 43(1), 77-96.

Carr, A.J. Ruaumoko-Inelastic Dynamic Analisys Program. Department of Civil Engineering, University of Canterbury, Christchurch, New Zealand 2000.

Celarec, D. and Dolšek, M. The impact of modelling uncertainties on the seismic performance assessment of reinforced concrete frame buildings. Engineering Structures. 2013; 52, 340-354.

CEN. Eurocode 2. Design of concrete structures - Part 1: General-Common rules for building and civil engineering structures. European committee for standardization; 2004. 
CEN. Eurocode 8. Design of structures for earthquake resistance. Part 1: General rules, seismic actions and rules for building. European committee for standardization; 2004.

Chopra, A.K., Goel, R.K. Capacity-demand-diagram methods for estimating seismic deformation of inelastic structures: SDOF systems. PEER Report 1999/02 Berkeley: Pacific Earthquake Engineering Research Center, University of California; 1999.

Chopra, A.K., Goel, R.K. A modal pushover analysis procedure for estimating seismic demand buildings. Earthquake Engineering and Structural Dynamics, 2002; 31(3), 561-582.

Chopra, A.K., Goel, R.K., Chintanapakdee, C. Evaluation of a modified MPA procedure assuming higher modes as elastic to estimate seismic demands. Earthquake Spectra 2004, 20(3), 757-778.

Chopra A.K. and Goel R.K. A modal pushover analysis procedure to estimate seismic demand for unsymmetric-plan buildings. Earthquake Engineering and Structural Dynamics, 2004; 33(8), 903-927.

Crowley, H., Bommer, J.J., Pinho, R., Bird, J.F. The impact of epistemic uncertainty on an earthquake loss model. Earthquake Engineering and Structural Dynamics, 2005; 34(14), 1635-1685.

Diaz-Alvarado, S.A., Pujades L.G., Barbat, A.H., Hidalgo-Leiva, D.A. and Vargas, Y.F. Capacity, damage and fragility models for steel buildings. A probabilistic approach. Bulletin of Earthquake Engineering. (Accepted)

Eads, L., Miranda, E., Krawinkler H. and Lignos D. An efficient method for estimating the collapse risk of structures in seismic regions. Earthquake Engineering and Structural Dynamics, 2013; 42(1), 25-41.

Egozcue, J.J., Barbat, A.H., Canas, J.A., Miquel, J. and Banda E., A method to estimate occurrence probabilities in low seismic activity regions. Earthquake Engineering and Structural Dynamics, 1991; 20(1), 43-60. 
Fajfar, P, Gaspersic, P. The N2 method for the seismic damage analysis of RC buildings. Earthquake Engineering and Structural Dynamics, 1996; 25(1), 31-46.

Fajfar, P. Capacity spectrum based on inelastic demand spectra. Earthquake Engineering and Structural Dynamics, 1999; 28(9), 979-993.

FEMA. HAZUS Earthquake loss estimation method, Federal Emergency Management Agency, Washington, DC 1999.

FEMA 440, Federal Emergency Management Agency, Improvement of Nonlinear Static Seismic Procedures, ATC-55 Draft, Washington, 2005.

Franchin, P., Pinto, P. and Pathmanathan, R. Confidence factor? Journal of Earthquake Engineering, 2010; 14(7), 989-1007.

Fragiadakis, M. and Vamvatsikos, D. Fast performance uncertainty estimation via pushover and approximate IDA. Earthquake Engineering and Structural Dynamics, 2010; 39(6), 683-703.

Freeman, S.A., Nicoletti, J.P., Tyrell, J.V. Evaluations of existing buildings for seismic risk - A case study of Puget Sound Naval Shipyard, Bremerton, Washington. Proc. $1^{\text {st }}$ U.S. National Conference of Earthquake Engineering. EERI, Berkeley, 1975; 113-122.

Freeman, S.A. Development and use of capacity spectrum method. Proc. $6^{\text {th }}$ U.S. National Conference of Earthquake Engineering. EERI, Seattle, 1998; CD-ROM.

Fujii, K. Nonlinear static procedure for multi-story asymmetric building considering bi-directional excitation. Journal of Earthquake Engineering, 2011; 15(2), 245-273.

Hancock, J., Bommer, J.J. and Sttaford, P.J. Numbers of scaled and matched accelerograms required for inelastic dynamic analyses. Earthquake Engineering and Structural Dynamics, 2008; 37(14), 15851607. 
Kreslin, M., Fajfar, P. The extended N2 method considering higher mode effects in both plan and elevation. Bulletin of Earthquake Engineering, 2012; 10(2), 695-715.

Lagomarsino, S, Giovinazzi, S. Macroseismic and mechanical models for the vulnerability and damage assessment of current buildings. Bulletin of Earthquake Engineering, 2006; 4(4), 415-443.

Lantada, N., Irrizari, J., Barbat, A. H., Goula, X., Roca, A., Susagna T. and Pujades, L. G. Seismic hazard and risk scenarios for Barcelona, Spain, using the Risk-UE vulnerability index method. Bulletin of Earthquake Engineering, 2010; 8(2), 201-229.

Lin, T., Haselton, C.and Baker J.W. Conditional spectrum-based ground motion selection. Part I: Hazard consistency for risk-based assessments. Earthquake Engineering and Structural Dynamics, $2013 ; 42(12), 1847-1865$.

Lin, T., Haselton, C.and Baker J.W. Conditional spectrum-based ground motion selection. Part II: Intensity-based assessments and evaluation of alternative target spectra. Earthquake Engineering and Structural Dynamics, 2013; 42(12), 1867-1884.

Melchers, R. E. Structural reliability analysis and prediction, Wiley, 1999.

Otani S. (1974). Inelastic analysis of RC frame structures. Journal of Structural Division. ASCE, 100(ST7), 1433-1449.

Park, Y.J., Ang, A.H.S. Mechanistic seismic damage Model for Reinforced Concrete. Journal of Structural Engineering ASCE, 1985; 111(4), 722-739.

Park, Y.J., Ang, A.H.S Kwei-Wen, Y. Seismic damage analysis of reinforced concrete buildings. Journal of Structural Engineering ASCE, 1985; 111(4), 740-757.

Poursha, M., Khoshnoudian, F. and Moghadam, A.S. A consecutive modal pushover procedure for estimating the seismic demands of tall buildings. Engineering Structures, 2009; 31(2), 591-599. 
Pujades, L.G., Vargas, Y.F., Barbat, A.H. and González-Drigo, J.R. Parametric model for capacity curves. Bulletin of earthquake engineering, 2015; 13(5), 1347-1376.

Reyes, J.C., Chopra, A.K. Three-dimensional modal pushover analysis of building subjected to two components of ground motions, including its evaluation for tall buildings. Earthquake Engineering and Structural Dynamics, 2010; 40(7), 789-806

Reyes, J.C., Chopra, A.K. Evaluation of three-dimensional modal pushover analysis for unsymmetricplan buildings subjected to two components of ground motion. Earthquake Engineering and Structural Dynamics, 2011; 40(13), 1475-1494.

Satyarno, I. Adaptive pushover analysis for the seismic assessment of older reinforced concrete buildings. Doctoral Thesis, Department of Civil Engineering, University of Canterbury, Christchurch, New Zealand 2000.

Vamvatsikos, D. and Cornell, C.A. The Incremental Dynamic Analysis. Earthquake Engineering and Structural Dynamics, 2002; 31(3), 491-514.

Vamvatsikos, D. and Fragiadakis, M. Incremental dynamic analysis for estimating seismic performance sensitivity and uncertainty. Earthquake Engineering and Structural Dynamics, 2010; 39(2), 141-163.

Vargas, Y.F., Pujades, L.G., Barbat, A.H. and Hurtado, J.E. Incremental dynamic analysis and pushover analysis of buildings. Computational Methods in Stochastic Dynamics; 2012; Vol 2. Springer.

Vargas, Y.F., Pujades, L.G., Barbat, A.H. and Hurtado, J.E. Capacity, fragility and damage in reinforced concrete buildings: a probabilistic approach. Bulletin of earthquake engineering, 2013a; 11(6), 2007-2032.

Vargas, Y.F., Pujades, L.G., Barbat, A.H. and Hurtado, J.E. Evaluación probabilista de la capacidad, fragilidad y daño sísmico en edificios de hormigón armado. Métodos numéricos para cálculo y diseño en ingeniería, 2013b; 29 (2), 63-78. 
Vargas, Y.F., Pujades, L.G., Barbat, A.H. and Hurtado, J.E. Probabilistic seismic damage assessment of RC buildings based on nonlinear dynamic analysis. Open Civil Engineering Journal, 2015; 9(1), 344-350.

Vargas Y.F., Pujades L.G., Barbat A.H., Hurtado J.E., Diaz-Alvarado S.A, Hidalgo-Leiva D.A. Probabilistic seismic damage assessment of reinforced concrete buildings considering directionality effects. Structure and Infrastructure Engineering, 2017. DOI: 10.1080/15732479.2017.1385089

Williams, S.M. and Sexsmith, R.G. Seismic Damage Indices for Concrete Structures: A State of the Art Review. Earthquake Spectra, 1995; 11(2), 319-349. 